\title{
Effect of peer support on improving self-management ability in peritoneal dialysis patients - a randomized controlled trial
}

\author{
Xiaolei Chen ${ }^{1 \#}$, Linghong Hua ${ }^{1 \#}$, Cen Zhang ${ }^{1}$, Zhenghong $\mathrm{Xu}^{2}$, Xiaodong $\mathrm{Cao}^{2}$, Yinghua Cai ${ }^{2}$ \\ ${ }^{1}$ Department of Nephrology, Wuxi People's Hospital, Wuxi, China; ${ }^{2}$ Nursing Department of Wuxi People's Hospital, Wuxi, China \\ Contributions: (I) Conception and design: X Chen; (II) Administrative support: Y Cai; (III) Provision of study materials or patients: C Zhang; (IV) \\ Collection and assembly of data: L Hua, X Cao; (V) Data analysis and interpretation: Z Xu; (VI) Manuscript writing: All authors; (VII) Final approval \\ of manuscript: All authors. \\ "These authors contributed equally to this work. \\ Correspondence to: Yinghua Cai. Department of Nursing, Wuxi People's Hospital, No. 299, Qingyang Road, Liangxi District, Wuxi 214023, China. \\ Email: 179098331@qq.com.
}

Background: Peritoneal dialysis (PD) is an ideal method for the treatment of chronic kidney disease. Its survival rate and quality of life depend on the quality of dialysis. The quality of dialysis depends on the compliance of patients with drugs and dialysis treatment, the choice of diet, the detection of complications and the monitoring and management of the disease. Therefore, the self-management of PD patients is particularly important. This study explored the role of peer support in improving the self-management ability of PD patients.

Methods: A total of 105 PD patients in a Chinese tertiary hospital were enrolled and divided into a control group (35 cases), a WeChat group (intervention group 1; 35 cases), and a face-to-face group (intervention group 2; 35 cases). During the 6-month follow-up, the control group were given individualized education, and the intervention group was given peer support.

Results: After the 6-month intervention, the self-management ability of the intervention group was significantly different from that of the control group $(\mathrm{P}<0.01)$. There were significant differences between the WeChat group and the face-to-face group with respect to hemoglobin and blood phosphorus $(\mathrm{P}<0.05)$. There were significant differences in prealbumin, hemoglobin, blood phosphorus and calcium levels between the intervention and control groups after 3 months and 6 months of intervention $(\mathrm{P}<0.01)$.

Conclusions: Peer support can effectively improve the self-management ability and biochemical indicators in PD patients.

Keywords: Peer support; peritoneal dialysis; self-management ability

Submitted Nov 12, 2020. Accepted for publication Mar 20, 2021.

doi: 10.21037/apm-21-219

View this article at: http://dx.doi.org/10.21037/apm-21-219

\section{Introduction}

Chronic kidney disease (CKD) is a progressive kidney disease with multiple etiologies and a high incidence, long course and poor prognosis. CKD seriously affects the life and health of patients, who choose peritoneal dialysis (PD), hemodialysis or kidney transplantation to maintain life (1). Of the dialysis methods, PD has good residual renal function protection, low cross-infection rate, and overall mortality at 1,2,3 and 4 years that is $8 \%$ lower than that of hemodialysis (2), which makes it an ideal dialysis method. However, although PD technology has been significantly improved recently, the survival rate and life quality of patients are still not ideal $(3,4)$. It is a long process for patients to complete dialysis treatment, pipeline nursing, monitoring body weight, blood pressure, diet and fluid intake. In this process, patients are prone to poor compliance, various complications, and high dialysis costs 
also increase the economic burden of PD patients and their families. PD patients are prone to physical, psychological and social problems, which lead to the decline of their quality of life, so self-management by PD patients is particularly important.

Peer support (PS) refers to providing substantial help to patients with similar diseases, physical conditions or experiences through various forms, as well as support in life practice, social and emotional aspects (5). In recent years, peer support has a good effect in self-management of patients with chronic diseases (6), mainly focusing on cancer, diabetes, hypertension and other diseases, and there are few similar studies on PD. Therefore, in this study, peer support was used as an intervention for improving the self-management behavior of $\mathrm{PD}$ patients, in order to provide the basis for the establishment and development of a home-based chronic disease management model that encourages improvement in the self-management ability, and thus quality of life (QOL), of PD patients. We present the following article in accordance with the CONSORT reporting checklist (available at http://dx.doi.org/10.21037/apm-21-219).

\section{Methods}

\section{Subjects}

PD patients were selected from among those who were followed up in the PD center of a tertiary hospital in Wuxi during January 2019. Inclusion criteria were: (I) age 18 -60 years, regular dialysis $\geq 1$ month, follow-up in the outpatient department of the PD center; (II) no peritonitis or other acute infections in the past month; (III) basic reading and comprehension, able to masteri QQ, WeChat and other network tools; (IV) informed consent and voluntary participation in this study. Exclusion criteria were: (I) severe heart, brain or lung complications; (II) previous or current mental diseases and severe cognitive impairment; (III) communication barriers and requiring care; (IV) did not participate in group activities more than three times as required. The formula for calculating the sample size was:

$$
N=2(\Sigma(S I 2) / k) /[\Sigma(\text { Xi mean } \times \text { mean }) 2 /(k-1)] \varphi
$$

Using a stratified sampling method, 105 subjects were divided into three groups: the control group, the WeChat group (intervention group 1) and the face-to-face group (intervention group 2) with 35, 35 and 35 cases respectively.

All procedures performed in this study involving human participants were in accordance with the Declaration of
Helsinki (as revised in 2013). The study was approved by ethics committee of Wuxi People's Hospital and informed consent was taken from all the patients.

\section{Interventions}

The patients in the control group were regularly followed up once a month for 6 months: (I) general condition and physical examination; (II) inspection of PD catheter outlet; (III) blood, urine and PD fluid samples taken; (IV) external short tube was replaced every 6 months; (V) feedback of examination results; (VI) individualized health education. At the same time, the patients in the intervention group participated in peer support and outpatient follow-up: establishment of a WeChat group between volunteers and the subjects; the face-to-face group had peer support provided in person by volunteers.

\section{Selection, training and assessment of peer support volunteers}

In this study, one peer support volunteer was responsible for 10-15 patients. Through recommendations of the fulltime medical staff in the PD center, a total of six volunteers were recruited with an average age of $48.67 \pm 3.44$ years and an average dialysis duration of $27.33 \pm 4.06$ months (regular dialysis $\geq 12$ months, age $\leq 60$ years old, good dialysis control (good self-feeling, reasonable control of various indicators), full ability to participate in peer support program, volunteered to undertake peer support work).

After recruitment of the volunteers, an education team comprising the researcher, full-time medical staff in the PD center and psychological counselors was established. The volunteers' training schedule was 1 hour a day for 5 days. The training included: (I) introduction of peer support projects; (II) introduction of peer support volunteers to the whole process; (III) PD knowledge and the harm and prevention of various complications; (IV) physical and mental health of PD patients; (V) improvement of communication and organizational skills of the volunteers. After the training, the volunteers were assessed on their PD knowledge and practical skills, mastery of the concept of peer support etc. before implementing the peer support program.

\section{Establishment of the volunteer-patient group}

The volunteers and subjects in the same group participated in a familiarization event organized by the researcher and the full-time medical staff of the PD center to meet each other. 
Table 1 Topics for peer support activities for peritoneal dialysis patients

\begin{tabular}{|c|c|c|c|c|}
\hline Period & Theme & Target & Content & Intervention focus \\
\hline $\begin{array}{l}\text { The third } \\
\text { month }\end{array}$ & $\begin{array}{l}\text { Tomorrow is better, } \\
\text { smile to life }\end{array}$ & $\begin{array}{l}\text { (I) Summarize the harvest and growth } \\
\text { of your peer support activities; } \\
\text { (II) face the future life positively }\end{array}$ & $\begin{array}{l}\text { (I) Looking back; } \\
\text { (II) true confession; } \\
\text { (III) summary }\end{array}$ & $\begin{array}{l}\text { (I) Share the fruits of your peer } \\
\text { support activities and discover your } \\
\text { positive changes; (II) imagine the } \\
\text { future }\end{array}$ \\
\hline
\end{tabular}

\section{Implementation of peer support intervention}

In the WeChat group, the volunteers and subjects participated in group activities from 18:00 to 19:00 hours every Friday, for a total of 24 group activities, 3 months. See Table 1 for details.

In the face-to-face group, activities were organized by the peer support volunteers, once every 2 weeks for 2 hours, for a total of 12 face-to-face group activities.

The peer support volunteers presided over each themed activity (content gained from semi-structured interviews with the PD patients in the early stage), including doubt solving and personal experience sharing. See Table 2 for details.

\section{Quality control in peer support}

At the end of each activity in the intervention group, the time and theme of the next activity were announced, and each participant received a reminder 1-2 days in advance; the researchers participated in and observed the whole process, recorded the content of each activity, identified problems, and gave feedback for timely solutions.

\section{Research indicators and tools}

\section{General information of the PD patients}

Based on literature review and expert interviews, the baseline data included social demographic data [sex, age, marital status, education, current working status, income, medical expense, payment method); PD-related data (primary disease, dialysis duration (months), dialysis frequency (bags/day)].

\section{Self-management scale of the PD patients}

Cronbach's $\alpha$ coefficient was 0.962 , the test-retest reliability was 0.937 , the content validity index was 0.963 , and the correlation coefficient between the items and the total score of the scale was $0.370-0.758$, indicating good reliability and validity of the Self-management scale. The scale included 5 dimensions and 28 items in total, namely: technical operation of fluid exchange (7 items), treatment of abnormal conditions in operation (4 items), diet management (5 items), complication monitoring (8 items), emotional management and social regression (4 items). All items were scored by the Likert 4-grade scoring system, with "never", "occasionally", "often" and "always" as 0, 1, 2 and 3 points respectively. The score of each dimension was the sum of the scores of the items in each dimension, and the total score of the scale was the sum of the scores of each dimension. The total score range was $0-84$, and the higher the score, the better the management ability.

\section{Biochemical indicators}

The related risk factors were taken as the core, and monitoring indicators were set, including albumin (Alb), prealbumin $(\mathrm{PA})$, hemoglobin $(\mathrm{Hb})$, phosphorus $(\mathrm{P})$, calcium $(\mathrm{Ca})$, creatinine $(\mathrm{Cr})$, and the urea clearance index $(\mathrm{Kt} / \mathrm{V})$. 
Table 2 Topics for peer support activities for peritoneal dialysis patients

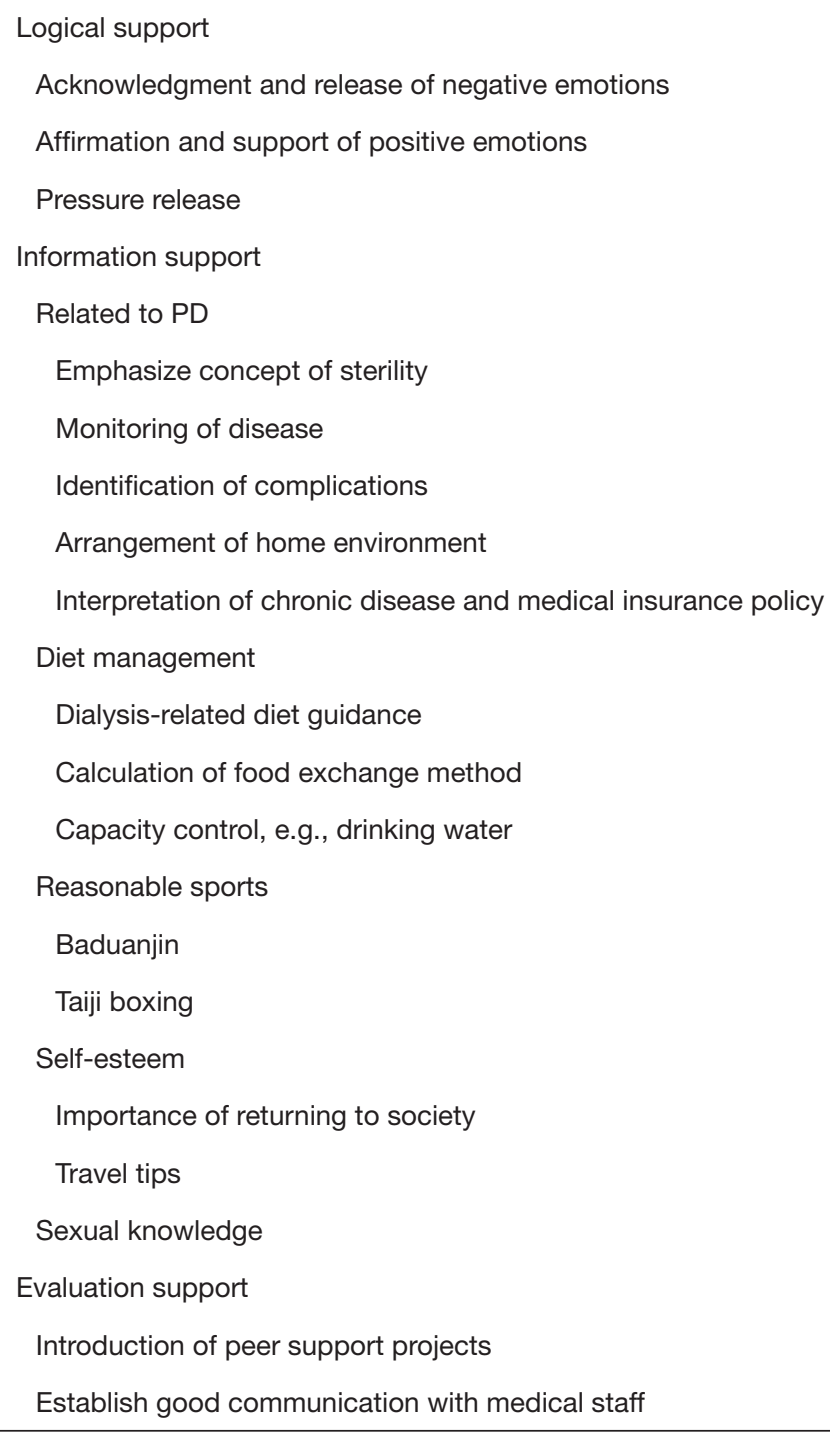

\section{Statistical analysis}

The data were collected and input into Epidata3.1 software by two people to establish a database. The data were imported into SPSS 17.0 software for statistical analysis. Chi-square test was used to compare the technical data of unordered variables. For measurement data comparison, $t$-test was used to analyze two independent samples with normal distribution, and repeated ANOVA analysis was used to analyze multiple independent samples with normal distribution/homogeneity of variance. Correction was conducted for further analysis if not consistent with normal distribution. $\mathrm{P}<0.05$ or $\mathrm{P}<0.01$ was considered as statistically significant.

\section{Results}

\section{Comparison of the general information of the three groups}

A total of 101 patients completed the study, of which 1 in the control group withdrew because of transferring to hemodialysis; 1 in the WeChat group withdrew for not participating in peer support activities three times; 2 in the face-to-face group withdrew because of transfer to another facility for medical treatment, and voluntary cessation. The general information of the three groups is shown in Table 3.

\section{Comparison of self-management ability before and after the intervention}

After 6 months of intervention, there were statistically significant differences in the total average score, diet management, complication monitoring, emotional management and social regression among the three groups $(\mathrm{P}<0.01)$. After the intervention, there were significant differences in the total average score, diet management, complication monitoring, emotional management and social regression between the WeChat and face-to-face groups $(\mathrm{P}<0.01)$. The total average score and the scores of diet management, complication monitoring, emotional management and social regression were compared for the two groups: at 6 months after intervention, there were significant differences between the control group and the WeChat group, and between the control group and the face-to-face group $(\mathrm{P}<0.05)$, but there was no difference in the other dimensions. At 6 months after the intervention, there were significant differences between the control group and the face-to-face group $(\mathrm{P}<0.05)$. See Table 4 for details.

\section{Comparison of biochemical indexes before and after the intervention}

After repeated ANOVA analysis, the PA, $\mathrm{Hb}, \mathrm{P}$, and $\mathrm{Ca}$ levels of the three groups were significantly different after 3 and 6 months of the intervention $(\mathrm{P}<0.01)$. Among the different intervention methods, the $\mathrm{PA}, \mathrm{Hb}, \mathrm{P}$, and Ca levels in the WeChat and face-to-face groups were significantly different at the different time points $(\mathrm{P}<0.05)$, the trend was significantly different $(\mathrm{P}<0.01)$, and there was interaction between intervention at the different time points $(\mathrm{P}<0.01)$. $\mathrm{PA}, \mathrm{Hb}, \mathrm{P}$, and $\mathrm{Ca}$ were compared at each time point: $\mathrm{PA}$, and $\mathrm{Ca}$ levels at 3 and 6 months of the intervention were statistically significant $(\mathrm{P}<0.05)$ between the control and WeChat group, and between the control and face-to-face 
Table 3 General information of the three groups

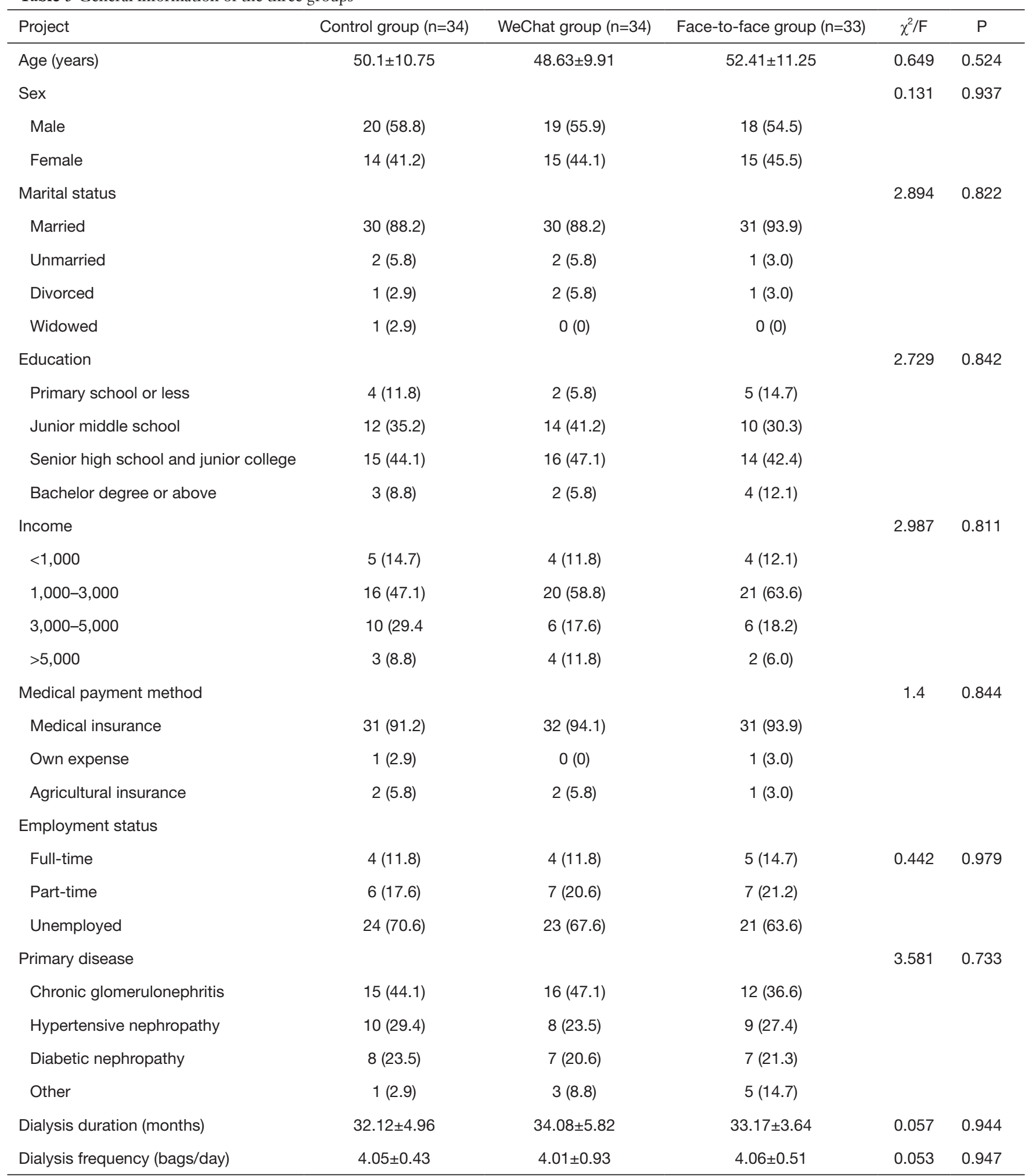

$\chi^{2}$, chi-square test; F, Fisher. There were no marked differences in the sex, age, marital status, education, current working status, income, medical expense, and payment method between three groups $(P>0.05)$. 
groups $(\mathrm{P}<0.05)$. There were significant differences in $\mathrm{Hb}$ and $\mathrm{P}$ between the control and face-to-face groups at 3 months of the intervention $(\mathrm{P}<0.05)$, but no difference in the other indexes; at the time point of 6 months, there were significant differences between the control and WeChat groups, between the WeChat and face-to-face groups, and between the control and face-to-face groups $(\mathrm{P}<0.05)$. See Table 5 for details.

After 6 months of intervention, there was a significant difference in the $\mathrm{Kt} / \mathrm{V}$ among the three groups $(\mathrm{P}<0.05)$. Among the different intervention methods, the difference in $\mathrm{Kt} / \mathrm{V}$ index before and after the intervention was statistically significant $(\mathrm{P}<0.05)$ only in the face-to-face group. Comparison of the $\mathrm{Kt} / \mathrm{V}$ index at the time point of 6 months, showed a significant difference between the control and face-to-face groups $(\mathrm{P}<0.05)$. See Table 6 for details.

\section{Participation in peer support activities by the intervention group}

The activity participation rate of the WeChat group and the face-to-face group was $91.2 \%$ and $93.9 \%$, respectively.

\section{Discussion}

\section{Importance of selection and training of volunteers for the development of peer support}

Generally, peer support requires training of the peer support volunteers first, so they can exert a positive influence through demonstration and their leading. Peer support volunteers play an important role because they have the same disease as their team members, and so they can understand the psychological problems of the patients, listen to and discuss problems together through similar life experiences, and give support. Therefore, their participation and organizational role are indispensable (7).

In this study, the peer support volunteers were trained for 5 days by an expert education team. Only two volunteers passed the PD knowledge assessment before the training, which is consistent with previous research (8). Although the volunteers were in a stable condition and their dialysis control was good, they lacked PDrelated knowledge. This emphasized the importance of selecting suitable volunteers, and training and assessing them to ensure the dissemination of quality peer support information.

\section{Effect of peer support on the self-management ability of PD patients}

With an increasing number of PD patients, problems such as poor self-management ability and poor emotional state caused by repeated treatment, it is difficult to effectively meet the requirements of patients solely through the support of medical staff (9). Self-management refers to individuals effectively using methods, skills and measures to help themselves achieve health goals; that is, patients help themselves to manage and control disease symptoms (10). Research shows that short-term interventions cannot improve the knowledge level of patients, and do not help improve the self-management ability of patients. Therefore, in this study, the duration of the peer support program was set at 6 months. According to the results of this study, there was no significant difference in the total average score and each dimension score of self-management ability in the control group before and after the intervention, whereas the total average score and each dimension score of the two intervention groups increased gradually over the course of the intervention, and the difference was statistically significant $(\mathrm{P}<0.01)$, indicating that peer support volunteers were assisting in the implementation of self-management behavior. Because volunteers and patients have the same disease and life experience, they can better understand each other's feelings and needs (11).

\section{Effect of peer support on the biochemical indexes of PD patients}

Research shows that PD patients have unique cardiovascular risk factors, including anemia, mineral metabolic disorder, protein energy consumption, inadequate dialysis, etc., all of which are related to an increase in all-cause mortality and cardiovascular mortality (12).

Chronic malnutrition is one of the main reasons for the decline in QOL and long-term survival rate of PD patients $(13,14)$. The total incidence of PD malnutrition has been reported as $53.2 \%(15)$. Studies show that the PA level changes before that of Alb, the former by $10 \%$, and the latter changed by $0.12 \mathrm{~g} / \mathrm{dL}$ following the same trend of (16). In the present study, the PA levels of the three groups before the intervention were all lower than the target value of $300 \mathrm{mg} / \mathrm{L}$ recommended by the guidelines. After intervention, PA levels in the WeChat group and the face-to-face group improved with increasing time of intervention, and the difference was statistically significant $(\mathrm{P}<0.01)$. Peer support encouraged the patients in the 
Table 4 Comparison of self-management ability before and after the intervention

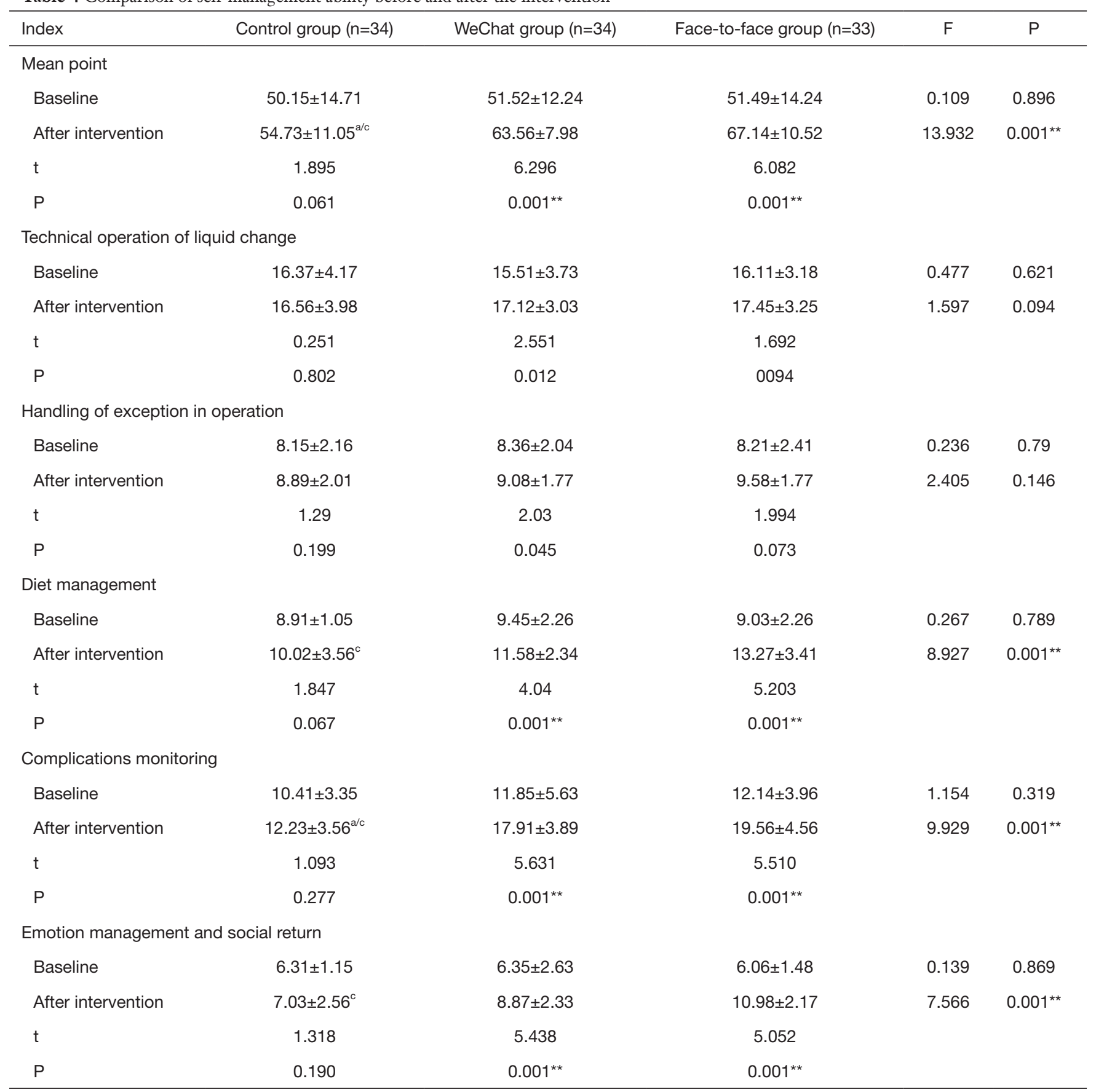

${ }^{a}$, control group vs. WeChat group; ${ }^{c}$, control group vs. face-to-face group. ${ }^{\star \star} \mathrm{P}<0.01$. t, Student's distribution; F, Fisher.

intervention group to establish better diet management. The intervention themes of the WeChat group and the face-to-face group were relevant to diet management, including "what to eat" (diet health education), "how to eat" (food exchange share method calculation), etc.
Renal anemia is a common complication of PD, and is one of the main risk factors for increased rehospitalization and mortality rates. It is closely related to QOL of PD patients (17). Therefore, in determining the topics for peer support, the concept of anemia was particularly emphasized: 
Table 5 Comparison of biochemical indexes before and after the intervention

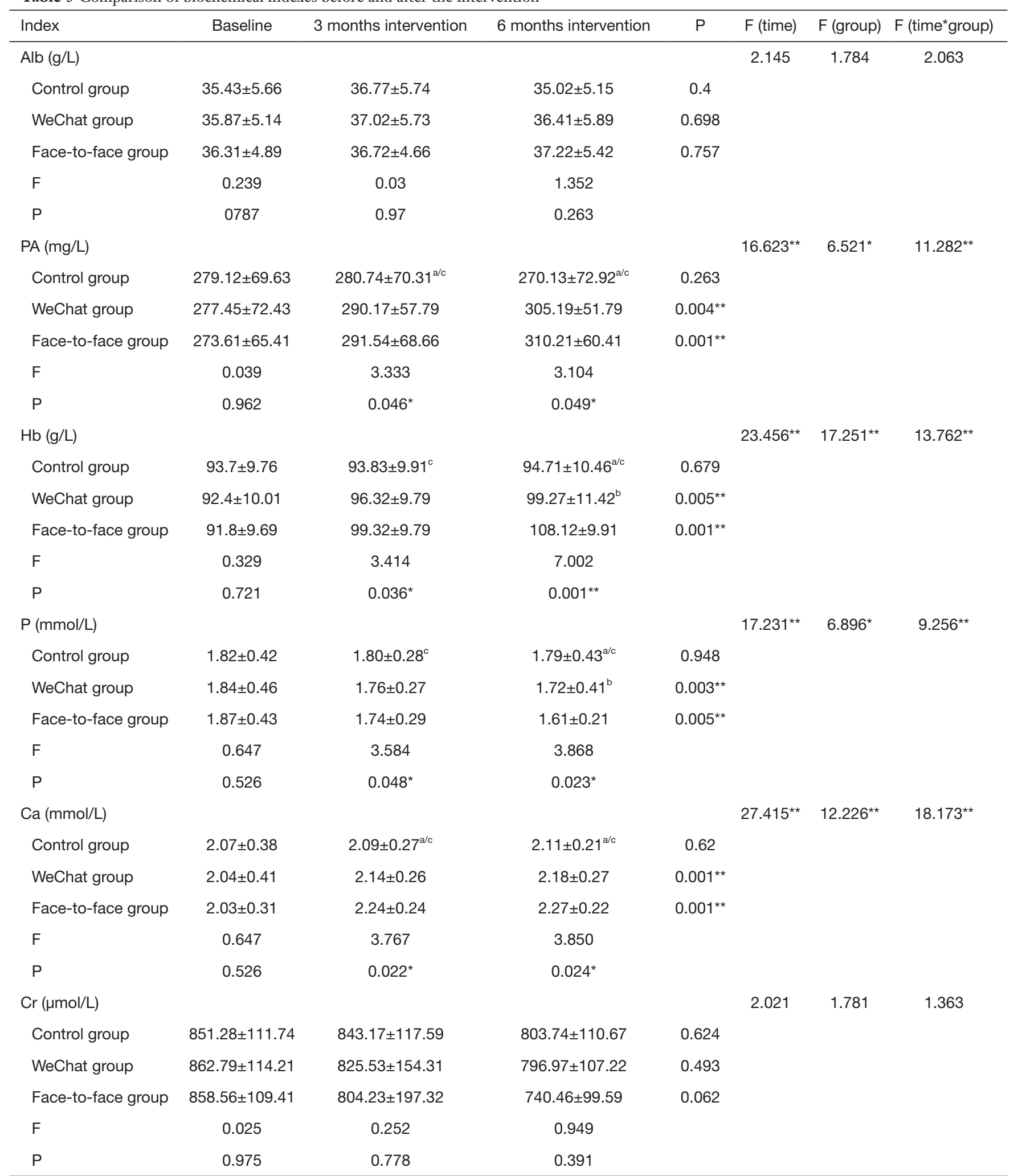

${ }^{a}$, control group vs. WeChat group; ${ }^{b}$, WeChat group vs. face-to-face group; ${ }^{\circ}$, control group vs. face-to-face group. ${ }^{\star} \mathrm{P}<0.05,{ }^{* \star} \mathrm{P}<0.01$. Alb, albumin; Ca, calcium; Cr, creatinine; Hb, hemoglobin; PA, prealbumin; P, phosphorus; F, Fisher. 
Table 6 Comparison of urea clearance index $(\mathrm{Kt} / \mathrm{V})$ before and after the intervention

\begin{tabular}{|c|c|c|c|c|c|}
\hline Time & \multicolumn{3}{|c|}{$\mathrm{Kt} / \mathrm{V}\left[\mathrm{L} /\left(\right.\right.$ week $\left.\left.\cdot 1.73 \mathrm{~m}^{2}\right)\right]$} & $\mathrm{F}$ & $\mathrm{P}$ \\
\hline Baseline & $1.7 \pm 0.21$ & $1.66 \pm 0.15$ & $1.72 \pm 0.42$ & 0.128 & 0.879 \\
\hline After intervention & $1.71 \pm 0.23^{\mathrm{c}}$ & $1.78 \pm 0.37$ & $1.91 \pm 0.25$ & 4.164 & $0.018^{*}$ \\
\hline $\mathrm{t}$ & 0.187 & 1.252 & 2.233 & & \\
\hline
\end{tabular}

${ }^{c}$, control group vs. face-to-face group. ${ }^{\star} \mathrm{P}<0.05$, t, Student's distribution; F, Fisher.

the importance of correcting anemia through diet and drug application according to doctor's advice, guiding patients how to identify possible anemia symptoms during the intervention period, and guiding patients on how to inject drugs, such as erythropoietin (EPO), etc. In this study, $\mathrm{Hb}$ in the WeChat group and the face-to-face group improved with increasing time of intervention, and the difference was statistically significant $(\mathrm{P}<0.01)$.

PD patients with renal dysfunction can develop to long-term $\mathrm{Ca}$ and $\mathrm{P}$ metabolic disorders, progressing to secondary hyperparathyroidism, renal osteopathy, vascular calcification etc. After the intervention, the $\mathrm{Ca}$ and $\mathrm{P}$ levels in the WeChat group and the face-to-face group gradually optimized with increasing time of intervention, and the difference was statistically significant $(\mathrm{P}<0.01)$, indicating that the patients were lacking relevant knowledge before the intervention, and the dietary compliance for high $\mathrm{Ca}$ and low $\mathrm{P}$ was poor. After the intervention, the patients were reasonably controlled through the support and experience sharing of the peer support volunteers, and their diets were reconstructed, which received good results.

In this study, $\mathrm{Cr}$ and $\mathrm{Kt} / \mathrm{V}$ were used as indicators of the clearance of toxins in PD patients. At present, the recognized dialysis adequacy standard is $\mathrm{Kt} / / \mathrm{V} \geq 1.7$, which is evaluated once every 6 months, and the dialysis regimen is adjusted according to the results. The results of this study showed that after 6 months of intervention, there were differences in $\mathrm{Kt} /$ $\mathrm{V}$ among the three groups, and the $\mathrm{Kt} / \mathrm{V}$ in the face-to-face group was better than that in the control group. Peer support improved dialysis treatment compliance, yielding a better dialysis efficacy in the intervention group.

\section{Analysis of the implementation of peer support program for PD patients}

From the results of this study, the effect of peer support in the WeChat group and the face-to-face group was obvious, but which of the two different forms of intervention had the advantage could not be absolutely determined, for the following reasons.

(I) There was no difference in the total average score and each dimension score between the WeChat and face-to-face groups after 6 months of intervention, which showed that both forms of peer support significantly improved the self-management ability of patients. Despite of the different intervention methods, the same information were delivered.

(II) In terms of the biochemical indexes, only $\mathrm{Hb}$ and $\mathrm{P}$ were different between the WeChat and faceto-face groups after 6 months of intervention, and the face-to-face group was better than the WeChat group. The differences in these indicators may be directly related to face-to-face communication. For example, the injection of EPO may be better mastered with face-to-face guidance.

Based on these results, we believe that either of the two intervention forms of peer support for PD patients used in this study can be selected. However, we should consider the ability of the patients and the cost of medical staff, and make decisions according to available resources. If it is convenient for the patients to travel, the activity site is fixed, and there is time allowed for medical staff participation, then peer support in the form of face-to-face communication can be selected. If considering the cost saving of medical staff, peer support intervention activities are not limited by time and place in the form of WeChat communication. However, no matter which form of peer support is chosen, we should actively guide and reliably track and monitor the quality of information in the peer support process, to ensure the scientific and effective role of peer support.

\section{Conclusions}

Peer support can effectively improve the self-management 
ability of PD patients and improve their biochemical indicators. However, there was no significant difference in the effect of the two different forms of peer support, which can be selected according to different situations. In addition, the recruitment and training of peer volunteers is the key factor in a peer support intervention, but there is currently no fixed or standardized model. Additionally, in China peer support is still in the stage of exploration and development, and needs to be further studied according to local conditions and existing resources.

\section{Acknowledgments}

Funding: None.

\section{Footnote}

Reporting Checklist: The authors have completed the CONSORT reporting checklist. Available at http://dx.doi. org/10.21037/apm-21-219

Data Sharing Statement: Available at http://dx.doi. org/10.21037/apm-21-219

Conflicts of Interest: All authors have completed the ICMJE uniform disclosure form (available at http://dx.doi. org/10.21037/apm-21-219). The authors have no conflicts of interest to declare.

Ethical Statement: The authors are accountable for all aspects of the work in ensuring that questions related to the accuracy or integrity of any part of the work are appropriately investigated and resolved. All procedures performed in this study involving human participants were in accordance with the Declaration of Helsinki (as revised in 2013). The study was approved by ethics committee of Wuxi People's Hospital and informed consent was taken from all the patients.

Open Access Statement: This is an Open Access article distributed in accordance with the Creative Commons Attribution-NonCommercial-NoDerivs 4.0 International License (CC BY-NC-ND 4.0), which permits the noncommercial replication and distribution of the article with the strict proviso that no changes or edits are made and the original work is properly cited (including links to both the formal publication through the relevant DOI and the license). See: https://creativecommons.org/licenses/by-nc-nd/4.0/.

\section{References}

1. Sarnak MJ, Amann K, Bangalore S, et al. Chronic Kidney Disease and Coronary Artery Disease: JACC State-of-theArt Review. J Am Coll Cardiol 2019;74:1823-38.

2. Weinhandl ED, Foley RN, Gilbertson DT, et al. Propensity-matched mortality comparison of incident hemodialysis and peritoneal dialysis patients. J Am Soc Nephrol 2010;21:499-506.

3. Okpechi IG, Nthite T, Swanepoel CR. Health—related quality of life in patients on hemodialysis and peritoneal dialysis. Saudi J Kidney Dis Transpl 2013;24:519-26.

4. Chow SK, Wong FK. Health-related quality of life in patients undergoing peritoneal dialysis: effects of anurse—led case management programme. J Adv Nurs 2010;66:1780-92.

5. Dennis CL. Peer support within a health care context: a concept analysis. Int J Nurs Stud 2003;40:321-32.

6. Assah FK, Atanga EN, Enoru S, et al. Community-based peer support significantly improves metabolic control in people with Type 2 diabetes in Yaoundé, Cameroon. Diabet Med 2015;32:886-9.

7. Simmons D, Cohn S, Bunn C, et al. Testing a peer support intervention for people with type 2 diabetes: a pilot for a randomised controlled trial. BMC Fam Pract 2013;14:5.

8. Marquis KH, Ware JE. Measures of diabetic patient knowledge, attitudes and behavior regarding self-care: Summary report. Santa Monica, California: RAND, 1979.

9. Subramanian L, Kirk R, Cuttitta T, et al. Remote Management for Peritoneal Dialysis: A Qualitative Study of Patient, Care Partner, and Clinician Perceptions and Priorities in the United States and the United Kingdom. Kidney Med 2019;1:354-65.

10. Newbould J, Taylor D, Bury M. Lay-led self-management in chronic illness: a review of the evidence. Chronic Illn 2006;2:249-61.

11. Hoey LM, Ieropoli SC, White VM, et al. Systematic review of peer-support programs for people with cancer. Patient Educ Couns 2008;70:315-37.

12. Kendrick J, Teitelbaum I. Strategies for improving longterm survival in peritoneal dialysis patients. Clin J Am Soc Nephrol 2010;5:1123-31.

13. Menon MK, Naimark DM, Bargman JM, et al. Long-term blood pressure control in a cohort of peritoneal dialysis patients and its association with residual renal function. Nephrol Dial Transplant 2001;16:2207-13.

14. Wang AY, Woo J, Lam CW, et al. Associations of serum fetuin-A with malnutrition, inflammation, atherosclerosis 
and valvular calcification syndrome and outcome in peritoneal dialysis patients. Nephrol Dial Transplant 2005;20:1676-85.

15. Chung SH, Heimbürger O, Stenvinkel P, et al. Association between inflammation and changes in residual renal function and peritoneal transport rate during the first year of dialysis. Nephrol Dial Transplant 2001;16:2240-5.

16. Neyra NR, Hakim RM, Shyr Y, et al. Serum transferrin and serum prealbumin are early predictors of serum albumin in chronic hemodialysis patients. J Ren Nutr 2000;10:184-90.

17. Sezer S, Ozdemir FN, Tutal E, et al. Prevalence and etiology of anemia in renal transplant recipients. Transplant Proc 2006;38:537-40.

(English Language Editor: K. Brown)

Cite this article as: Chen $\mathrm{X}$, Hua L, Zhang C, Xu Z, Cao X, Cai Y. Effect of peer support on improving self-management ability in peritoneal dialysis patients-a randomized controlled trial. Ann Palliat Med 2021;10(3):3028-3038. doi: 10.21037/ apm-21-219 